\title{
A New Therapeutic Option for Chronic Hepatitis B: Reduced Dose and Shorter Duration of a Combination Therapy with Pegylated Interferon and Entecavir
}

\author{
Mahtab MA ${ }^{1 *}$, Tabassum $\mathrm{S}^{2}$, Nesa $\mathrm{A}^{2}$, Jahan $\mathrm{M}^{2}$, Khan $\mathrm{MSI}^{3}$, Akbar $\mathrm{SMF}^{4,5}$ \\ ${ }^{I}$ Department of Hepatology, Bangabandhu Sheikh Mujib Medical University, Dhaka, Bangladesh, \\ ${ }^{2}$ Department of Virology, Bangabandhu Sheikh Mujib Medical University, Dhaka, \\ Bangladesh, ${ }^{3}$ Department of Anatomy and Embryology, Ehime University Graduate School of Medicine, \\ Ehime, Japan, ${ }^{4}$ Department of Analytical Pathology, Proteo-Science Center, Ehime University Graduate \\ School of Medicine, Ehime, Japan; ${ }^{5}$ Miyakawa Memorial Research Foundation, Tokyo, Japan.
}

\begin{abstract}
Background: Although several drugs are available for treatment of chronic hepatitis B (CHB), the outcome is still far from being satisfactory. The study was conducted to develop a therapeutic strategy for CHB by a combination therapy with reduced dose and duration of antiviral drugs.

Objectives: Therapeutic effects of reduced dose and shorter duration of combination of pegylated interferon (Peg-IFN) and entecavir were evaluated in patients with CHB with two control groups.

Methods: Fifty-four patients with CHB were treated with reduced dose of Peg-IFN (90 microgram in spite of standard dose of 180 microgram $)$ and standard dose of entecavir $(0.5 \mathrm{mg})$ for reduced duration of 24 weeks (Case of group). There were two control groups that adhered to inclusion and exclusion criteria. Patients of Control group-1 ( $\mathrm{n}=50)$ received regular doses (180 microgram) of Peg-IFN, once weekly for 48 consecutive weeks. Patients of Control group- $2(n=50)$ were treated with regular does of entecavir $(0.5 \mathrm{mg}$, daily) for 48 weeks.

Results: The treatment regimens were safe for all patients. At the end of therapy (EOT), hepatitis B virus DNA negativity (HBV DNA $<250$ copies $/ \mathrm{mL}$ ) was found in $67 \%, 50 \%$ and $80 \%$ of patients of Control Group-1, Control group-2, and case group, respectively. HBV DNA negativity was found in more patients in cases (89\% from 67\%) 24 weeks after EOT. However, it declined in patients of Control group-1 (80\% to $56 \%)$ and remained almost similar in Control group-2 (50\% versus 56\%). There was no significant difference in alanine transaminase (ALT) negativity and hepatitis $\mathrm{E}$ antigen ( $\mathrm{HBeAg}$ ) seronegativity among 3 groups at EOT and 24 weeks after EOT.

Conclusion: A patient-friendlytherapeutic strategy with reduced dose of Peg-IFN and regular dose of entecavir for shortened duration for CHB patientshave been documented and it would be also cheap for usage of patients with CHB.
\end{abstract}

Keywords: Chronic hepatitis B, Pegylated interferon, Entecavir, Combination therapy

\section{Introduction}

About 2 billion people of the world have been infected with hepatitis $\mathrm{B}$ virus and according to the World Health Organization (WHO) estimates about 240 million subjects are chronically infected with HBV. About 20-40\% of total chronic HBV-infected patients are at risk of developing chronic hepatitis, cirrhosis of liver and hepatocellular carcinoma. ${ }^{1-4}$ Bangladesh is no exception to this scenario and about 30-80 million people of this country are chronic HBV infected. Studies have shown that HBV is the major cause of all forms of liver diseases in Bangladesh. ${ }^{5-7}$

Correspondence: Dr. Mamun Al-Mahtab, Chairman, Department of Hepatology Bangabandhu Sheikh Mujib Medical University, Shahbagh, Dhaka-1000, Bangladesh..e-mail: shwapnil@agni.com; ORCID: 0000-0003-3728-3879
To treat chronic HBV infections, currently available therapeutic options include both parenteral and oral agents, which act on various host and viral targets. Randomized-controlled trials (RCTs) have shown the utility of these drugs in reduction of hepatitis B virus (HBV) replication, containment of liver damages and delaying of progression to complications in some patients with CHB ${ }^{8-10}$ However, the sustained therapeutic efficacy of these drugs is negligible. ${ }^{11-12}$

Considering the adverse effects of $\mathrm{HBV}$ and its implications on health care delivery system, there remains a pressing need to develop new and novel therapeutic regimens for patients with chronic 
HBV infections and their complications. Based on the present evidences, it appears better therapeutic regimen for $\mathrm{HBV}$ may be optimized either by discovering new drugs. However, it seems that the target may not be achieved in next one or more decades because control of cccDNA seems to be an unachievable goal and at present it seems that emergence of any new drug in this field may be extremely difficult. On the other hand, there remain approaches to get better therapeutic regimens by manipulating dose, duration and therapeutic designs of commerciallyavailable therapeutic agents for CHB.

The rationale for combination therapy for $\mathrm{CHB}$ patients includes the possibility that an additive effect of various medications may achieve; (i) more effective viral suppression, (ii) increased immune modulation, (iii) better control of liver damage, and (iv) decreased incidence of drug resistance. In most cases of combination therapy, therapeutic efficacy of two nucleoside analogs (NAs) have been checked. ${ }^{13-14}$ Some studies have also reported the utility of combination of NA and interferon (IFN) for treating CHB patients. ${ }^{15}$ However, more information is required about the design of combination therapy; (1) is there any opportunity to reduce dose and duration drugs of combination therapy and (2) the real potential of combination therapy in treatment-naïve patients with $\mathrm{CHB}$ as most trials of combination therapy have been conducted in NA-resistant patients. ${ }^{16}$

On the basis of these observations, the safety and clinical efficacy of a combination therapy of reduced dose of Peg-IFN for shortened duration and regular dose of entecavir for shortened duration has been evaluated in treatment-naïve patients with $\mathrm{CHB}$ at Bangladesh.

\section{Materials and Methods}

Patients: A total of 154 treatment-naïve patients with $\mathrm{CHB}$ were enrolled in this study. Informed consents were obtained from all patients after explaining the nature and purpose of the study. The study protocol conformed to ethical guidelines of the 1975 Declaration of Helsinki as reflected in a priori approval by the appropriate institutional review board. Also, a departmental review board of Bangabandhu Sheikh Mujib Medical University, Dhaka, Bangladesh provided permission to conduct the study. The study was enrolled in ClinicalTrial.gov [NCT01589952]. The study represents an open level clinical trial with commercially-available drugs. The study was conducted at the Department of Hepatology, Bangabandhu Sheikh Mujib Medical University, Dhaka, Bangladesh. The study was conducted from and all patients were followed for 24 weeks after end of treatment. The study was conducted from January 2014 to June 2016

The treatment naïve patients with $\mathrm{CHB}$ were enrolled in this study. Inclusion criteria for the study included: (1) positive for $\mathrm{HBsAg}$ for more than 6 months, (2) positive or negative for HBeAg, (3) elevated serum ALT levels (upper limit of normal <42U/L) (4) serum HBV DNA positive (5) negative for serological markers of hepatitis $\mathrm{C}$ virus, IgM type antibody to hepatitis $\mathrm{A}$ virus, and hepatitis $\mathrm{E}$ virus, and (6) consumption of alcohol of less than $20 \mathrm{~g} / \mathrm{day}$, and (7) pregnancy. These patients were under follow up for more than 6 months prior to their enrollment in this study. All patients were treatment naïve and none of the patients received any antiviral or immune modulator drugs during last 6 months.

The exclusion criteria included (1) diagnosis of liver cirrhosis, (2) evidence of hepatocellular carcinoma, and any contrast to inclusion criteria. Also, patients receiving previous antiviral and immune modulatory therapy were excluded from the study.

Out of the total 154 patients, 54 patients received regular dose Peg-IFN (90 microgram), weekly for 24 weeks and regular dose of entecavir $(0.5 \mathrm{mg})$ for 24 weeks (Casegroup) (figure 1 A). Fifty patients received regular dose of Peg-IFN (180 microgram), once weekly, for 48 weeks (Control group-1) (figure 1B). The patients of Control group-2 received regular dose of entecavir $(0.5$ $\mathrm{mg}$, daily) for 48 weeks (fig. 1C). The patients were assessed for biochemical, virological, and immunological parameters before and at different time points at the reference laboratory of BSMMU, Dhaka, Bangladesh.

Haematological tests: Complete haematological tests were conducted to characterize the blood cell populations, according to conventional procedures. In addition, liver function parameters (albumin, alkaline phosphatase, total protein, platelet counts, and bilirubin tests) were used to monitor any potential worsening of the disease during the course of the study. Serum creatinine was measured to 
assess the kidney function of patients. ${ }^{17}$

Biochemical, serological, and virologicaltests: Serum alanine aminotransferase (ALT) levels and prothrombin time were assessed by a tertiarylevel professional laboratory, as previously described. ${ }^{17}$ The cutoff value for abnormal ALT was $42 \mathrm{U} / \mathrm{L}$. HBeAg and anti-HBe were checked commercially by an enzyme-linked immunosorbent assay (ELISA) using a commercial kit (Abbott Labs, Chicago, IL, USA). Serum HBV DNA was quantified using a polymerase chain reaction (PCR) method with a commercial kit (Amplicon HBV Monitor Assay, RT-PCR, Roche Molecular Systems, CA, USA). The detection limit of HBV DNA was 250 copies of $\mathrm{HBV} \mathrm{DNA} / \mathrm{ml}$ or greater.

Statistical analysis: Data were analysed by unpaired $t$ tests if the data were normally distributed and by the Mann-Whitney rank-sum test if they were skewed. Data were expressed as means \pm standard error of mean (mean \pm SEM). Differences were considered significant if $p<0.05$.

\section{Results}

A total of 154 patients were enrolled in this study. All of them have been suffering from chronic hepatitis B. The baseline data of the patients were also assessed (table I).

Safety: All patients of Case group and Control group-1 and Control group-2 completed the therapy, as designed. Also, they were available for follow up at 24 weeks after end of treatment (EOT). The levels of ALT increased in some patients, but abnormal elevation of ALT ( 5 times of the upper limit of normal (ULN) or 5 times higher compared to pretreatment levels) was not detected in any patient. The parameters of liver function and kidney functions also revealed that these therapeutic approaches were safe for all patients.

Table I: Clinical profiles of the patients

\begin{tabular}{llll}
\hline Parameters & $\begin{array}{l}\text { Control } \\
\text { group-1 }\end{array}$ & $\begin{array}{l}\text { Control } \\
\text { group-2 }\end{array}$ & Case group \\
\hline Numbers & 50 & 50 & 54 \\
Male: Female & $42: 8$ & $40: 10$ & $44: 10$ \\
Age & $18-48$ years & $19-40$ years & $16-52$ years \\
$\begin{array}{l}\text { HBV DNA } \\
\text { copies/ml) }\end{array}$ & $1.35 \times 10^{3} .-$ & $1.6 \times 10^{3} .-$ & $1.1 \times 10^{4} .-$ \\
$*$ ALT (IU/L) & $68.4 \pm 37.5$ & $70.6 \pm 44.8$ & $77.7 \pm 68.5$ \\
\hline
\end{tabular}

*ALT; alanine aminotransferase. The levels of ALT on the day of study commencement have been shown. All patients had elevated ALT during their enrollment in the study.

Role of therapy on ALT levels: All patients of case group and control groups had elevated ALT during their enrollment ( 3 months prior to start of treatment). However, the levels of ALT showed considerable fluctuations and some patients had ALT below upper level of normal (ULN) on the day of treatment commencement. The levels of ALT decreased to within upper limit of normal in $70 \%, 76 \%$ and $80 \%$ patients of control group-1, control group-2 and case group, respectively. No significant difference was observed about ALT levels at this point among three groups of the study population $(p>0.05)$.

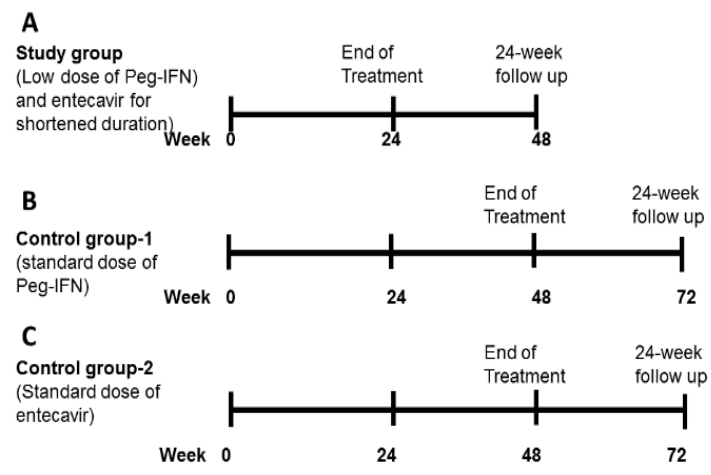

Figure 1: The therapeutic design of Study Group with reduced dose and reduced duration of combination of Peg-IFN and entecavir [A], Control group-1 with full dose of Peg-IFN [B], and Control group-2 with regular dose of entecavir [C].

On-treatment antiviral effects of different therapeutic regimens in $\mathrm{CHB}$ patients: All patients in this cohort had detectable levels of HBV DNA in the sera on the day of start of therapy. Patients of control group- 1 and control group-2 were evaluated 48 weeks after study commencement (EOT). Forty, out of 50 patients $(80 \%)$ of control group-1 and 25 of $50(50 \%)$ patients of control group-2 showed undetectable HBV DNA (HBV DNA<250 copies/ml) at EOT, respectively (48 weeks after study commencement) (table II). Patients of Case group receiving low dose of Peg-IFN and entecavir for reduced duration received treatment for 24 weeks. HBV negativity (HBV DNA $<250$ copies/ml) was 
detected in 36 of $54(67 \%)$ patients of the Casegroup at EOT (24 weeks after therapy commencement) (table II).

Role of combination therapy with reduced dose and short duration of combination therapy on sustained control of HBV DNA in CHB patients: In the present study, combination therapy with reduced dose and shorter duration was given in 54 patients (Case group) for 24 weeks. At the end of treatment, 36 of $54(67 \%)$ patients became negative for HBV DNA (HBV DNA<250 copies $/ \mathrm{ml}$ ) in the sera. Then, these patients received neither any antiviral drug nor any immune modulators during the next 24 weeks of follow up period. At the end of 48 weeks (24 weeks of of-treatment follow up), HBV DNA negativity was increased to 48 patients of 54 patients $(89 \%)$ of this group (table II).

Table II: Kinetics of HBV DNA in studies publish, control group-2 and group

\begin{tabular}{|c|c|c|}
\hline & $\begin{array}{l}\text { HBV DNA- } \\
\text { positive }\end{array}$ & $\begin{array}{l}\text { HBV DNA- } \\
\text { negative }\end{array}$ \\
\hline \multicolumn{3}{|c|}{$\begin{array}{l}\text { Control group-1 (Full dose of pegylated interferon for } 48 \\
\text { weeks) }\end{array}$} \\
\hline 0 week & 50 & 0 \\
\hline 24 weeks & $12(24 \%)$ & $38(76 \%)$ \\
\hline 48 weeks (EOT) & $10(20 \%)$ & $40(80 \%)$ \\
\hline $\begin{array}{l}72 \text { weeks }(24 \text { weeks } \\
\text { follow up) }\end{array}$ & $22(44 \%)$ & $28(56 \%)$ \\
\hline \multicolumn{3}{|c|}{ Control group-2 (regular dose of entecavir for 48 weeks) } \\
\hline 0 week & 50 & 0 \\
\hline 24 weeks & $45(90 \%)$ & $5(10 \%)$ \\
\hline $\begin{array}{l}48 \text { weeks } \\
\text { (end of treatment) }\end{array}$ & $25(50 \%)$ & $25(50 \%)$ \\
\hline $\begin{array}{l}72 \text { weeks } \\
\text { (24-weeks follow up) }\end{array}$ & $23(46 \%)$ & $27(54 \%)$ \\
\hline \multicolumn{3}{|c|}{$\begin{array}{l}\text { Case group (Reduced dose of pegylated interferon and regular } \\
\text { dose of entecavir for } 24 \text { weeks) }\end{array}$} \\
\hline 0 week & 54 & 0 \\
\hline $\begin{array}{l}24 \text { weeks } \\
\text { (end of treatment) }\end{array}$ & 18 & $36(67 \%)$ \\
\hline $\begin{array}{l}48 \text { weeks } \\
\text { ( } 24 \text {-weeks follow up) }\end{array}$ & 6 & $(89 \%)$ \\
\hline
\end{tabular}

$p<0.05$ Compared to 24 weeks follow up of Control group-1 and Control group-2
This contrasted markedly with the HBV DNA status of patients of control groups that received full doses of Peg-IFN for 48 weeks or full doses of entecavir for 48 weeks. Although 40 of 50 patients receiving Peg-IFN became negative for HBV DNA after 48 weeks of therapy, only 28 patients remained $\mathrm{HBV}$

DNA negative after 24 weeks of off-treatment follow up $(p<0.05)$. Sustained HBV DNA negativity was seen in only 27 patients of Control Group-2,24 weeks after EOT (table II). This was also significantly lower than those of the patients receiving combined therapy $(p<0.05)$.

\section{Discussion}

The study presented here is a pilot study and was accomplished in real life situation of Bangladesh, a developing country of Asia with a population of 160 million and harboring about 8 million chronic HBV-infected patients. ${ }^{5-7}$ The study was undertaken to address multiple variable for designing safer, more efficacious and costeffective therapeutic regimen for treating patients with CHB.

Here, it was applied a combination therapy containing both entecavir and Peg-IFN in CHB patients. The dose of Peg-IFN was reduced to 90 microgram from standard dose of 180 microgram and the duration of therapy was reduced to 24 weeks from standard one of 48 weeks or more. The outcome of this new regimen of therapy was compared with two groups of control patients; one receiving standard regimen of Peg-IFN (180 microgram, once a week for 48 weeks) and the other received standard regimen of entecavir, 0.5 mg daily for 48 weeks. At EOT, HBV DNA negativity was recorded in $80 \%, 50 \%$ and $67 \%$ CHB patients with Control group-1, Control group-2 and Casegroup, respectively. This data inspired optimism about antiviral potentiality of low dose and short duration of combination therapy in CHB patients. However, more important information was provided when data of follow up durations were analyzed. HBV DNA negativity was not improved even though the patients received entecavir for next 24 weeks (table II). In contrast, HBV DNA negativity was increased to $89 \%$ from $67 \%, 24$ weeks after end of treatment with reduced dose and short duration 
of combination therapy with combination therapy with low dose of Peg-IFN and regular dose of entecavir (table II).

As there is no comparable study of this nature, it may be difficult to make logical discussion about sustained HBV DNA negativity of this approach. However, Liaw et al have reported that lower dose and shorter duration of Peg-IFN therapy is endowed with inferior therapeutic potential in CHB patients. ${ }^{14}$ The cause of better therapeutic effect of this approach remains to be confirmed in future studies. However, it may be possible that IFN would provide an appropriate immunological milieu for action of entecavir. This effect has been shown in treatment-naïve patients and it is yet to examine the effect of our approach in NAresistant patients with $\mathrm{CHB}$.

There are some limitations of the present study. This is not a randomized-controlled trial and also the study population was not substantially large. However, the safety profile and antiviral potentiality of this approach would induce more studies in different populations. So that better designs of therapeutic regime may be developed for CHB patients. Also, the cost-effectiveness of this approach should be considered in the context of poorly-developed health care delivery system and hepatitis management strategy of developing countries that harbour most of the CHB patients but lack national insurance system to support treatment of these patients. IFN is a costly drug. If a therapeutic regimen can show comparable efficacy with half dose of IFN, that should be considered for wide-spread clinical trial. Also, this may be a friendly therapeutic approach for comparatively elder patients with CHB who are unable to tolerate full doses of IFN for adverse effects. In combination, this pilot study may be considered in developing countries and elder patients for treatment of CHB.

\section{Conclusion}

A safe and effective regimen of therapy for CHB patients has been documented by decreasing dose and duration of antiviral drugs and subjected those as a combination therapy. The study was characterized by an open-level clinical trial with patient's consents, permission of institution and registering at ClinicalTrial.gov [NCT01589952].
The outcomes of the study deserve serious consideration as this will reduce the cost of therapy and down regulate adverse effects of therapy. This study is one of the first endeavours of this type and would be accepted highly in resource-constrained countries that are heavily burdened with patients of chronic HBV infection.

\section{Acknowledgement}

The study was supported in part by a grant-in-aid from Bangabandhu Sheikh Mujib Medical University, Dhaka, Bangladesh.

Conflict of interest: There is no conflict of interest about this article.

\section{References}

1. Global hepatitis report, 2017 at who.int World Health Organization. cited 2018 May 2.

2. Busch K, Thimme R. Natural history of chronic hepatitis B virus infection. Med Microbiol Immunol. 2015;204:5-10.

3. Chang ML, Liaw YF. Hepatitis B flares in chronic hepatitis B: pathogenesis, natural course, and management. J Hepatol. 2014;61:1407-17.

4. Zhang YY, Hu KQ, Duan Z. New perspective on the natural course of chronic HBV infection Front Med. doi: 2014; 8:129-34. 10.1007/s11684-014-0339-x. Epub 2014 May 29.

5. Mahtab M. Epidemiology of Viral Hepatitis and Liver Diseases in Bangladesh. Euro asian J Hepato gastroenterol. 2015;5: 26-29

6. Ashraf H, Alam NH, Rothermundt C, Brooks A, Bardhan P, Hossain L, Salam MA, Hassan MS, Beglinger C, Gyr N. Prevalence and risk factors of hepatitis B and C virus infections in an impoverished urban community in Dhaka, Bangladesh. BMC Infect Dis. 2010;10: 208.

7. Mahtab MA, Rahman S, Karim MF, Khan M, Foster G, Solaiman $\mathrm{S}$ et al. Epidemiology of hepatitis B virus in Bangladeshi general population. Hepatobiliary Pancreat Dis Int. 2008;7: 595-600.

8. Zoulim F, Locarnini S. Optimalmanagement of chronic hepatitis Bpatients with treatment failure and antiviral drug resistance.Liver Int. 2013;33 Suppl 1:116-24.

9. Wiegand J, van Bommel F, Berg T. Management of chronic hepatitis B: status and challenges beyond treatment guidelines. Semin Liver Dis.2010; 30:361-77.

10. Lin SM, Sheen IS, Chien RN, Chu CM, Liaw YF. Long-term beneficial effect of interferon therapy in patients with chronic hepatitis B virus infection. Hepatology. 1999;29: 971-75. 
11. Wilt TJ, Shamliyan T, Shaukat A, Taylor BC, MacDonald R, Yuan JM, et al. Management of chronic hepatitis B. Evid Rep Technol Assess (Full Rep). 2008;174:1-671.

12. Taylor BC, Yuan JM, Shamliyan TA, Shaukat A, Kane RL, Wilt TJ. Clinical outcomes in adults with chronic hepatitis B in association with patient and viral characteristics: A systematic review of evidence. Hepatology. 2009;49 Suppl:S85-95.

13. Ghany MG, Feld JJ, Zhao X, Heller T, Doo E, Rotman Y, et al. Randomised clinical trial: the benefit of combination therapy with adefovir and lamivudine for chronic hepatitis B. Aliment Pharmacol Ther. 2012;35: 1027-35.

14. Chen Y, Ju T. Comparative meta-analysis of adefovir dipivoxil mono therapy and combination therapy of adefovir dipivoxil and lamivudine for lamivudine-resistantchronic hepatitis B.Int J Infect Dis. 2012;16:e152-58.

15. Enomoto M, Nishiguchi S, Tamori A, Kobayashi S, Sakaguchi H, Shiomi S, et al. Entecavir and interferon- $\alpha$ sequential therapy in Japanese patients with hepatitis $B$ e antigen-positivechronic hepatitis B.J Gastroenterol. 2013;48:397-404.
16. Liaw YF, Jia JD, Chan HL, Han KH, Tanwandee $\mathrm{T}$, Chuang WL, et al. Shorterdurations and lowerdoses of peginterferon alfa-2a are associated with inferior hepatitis Be anti gensero conversion rates in hepatitis $B$ virusgenotypes $B$ or C.Hepatology. 2011;54:1591-99.

17. Al-Mahtab M, Rahman S, Akbar SM, Kamal M, Khan MS. Clinical use of liver biopsy for the diagnosis and management of inactive and asymptomatic hepatitis $\mathrm{B}$ virus carriers in Bangladesh. J Med Virol. 2010;82:1350-54.

18. Zhou J, Wu X, Wei W, You H, Jia J, Kong Y.A Meta-Analysis of the Efficacy of InterferonMonotherapy or Combined with Different Nucleos (t) ide Analogues for Chronic Hepatitis B. Int J Environ Res Public Health. 2016; 21:13.

19. Kim SK, Kim SR, Imoto S, Tohyama M, Otono Y, Tamura Tet al. Recent Advances in the Management of Chronic Hepatitis B Including Suppression of Hepatocellular Carcinoma by Entecavir and Interferon. Oncology. 2015;89 Suppl 2:60-9. 